\title{
Estudio arqueométrico de cerámicas procedentes de cinco alfares celtibéricos del sistema ibérico central
}

\author{
J. IGEA ${ }^{1}$, P. LAPUENTE ${ }^{\text {, }}$ M. E. SAIZ ${ }^{2}$ F. BURILLO², J. BASTIDA ${ }^{3}$, J. PÉREZ-ARANTEGUI ${ }^{4}$ \\ ' Departamento de Ciencias de la Tierra, Facultad de Ciencias. Universidad de Zaragoza. \\ ${ }^{2}$ Departamento de Ciencias de la Antigüedad. Facultad de Ciencias Sociales y Humanas de Teruel. Universidad de Zaragoza. \\ ${ }^{3}$ Departamento de Geología. Universidad de Valencia. \\ ${ }^{4}$ Departamento de Química Analítica, Facultad de Ciencias. Universidad de Zaragoza.
}

\begin{abstract}
El objeto de este trabajo es la caracterización arqueométrica de la producción cerámica en un conjunto de 5 alfares celtibéricos ubicados en el Sistema Ibérico Central. En estos talleres, cuya cronología de funcionamiento se centró en los siglos III-II a. C., se fabricaban cerámicas finas a torno que han sido agrupadas en vajilla de almacenaje/transporte, vajilla de servicio y vajilla de mesa. El estudio arqueométrico se ha dirigido a la caracterización de sus diferentes pastas cerámicas desde un punto de vista mineralógico, textural y químico, con el propósito de crear grupos de referencia de cada alfar y establecer los procesos tecnológicos empleados en su manufactura. Las muestras fueron analizadas mediante microscopía óptica convencional $(\mathrm{MO})$, difracción de rayos $\mathrm{X}(\mathrm{DRX})$, análisis textural por tratamiento digital de imágenes y análisis químico mediante espectrometría de emisión atómica con plasma de acoplamiento inductivo (ICP-AES). Los resultados obtenidos a partir de las distintas técnicas utilizadas han llevado a la distinción de 8 tipos de pastas. Las arcillas utilizadas como materia prima en todos los centros productores, fueron de composición illítica-moscovítica con inclusiones naturales de litología y tamaño variables, previamente trituradas. Salvo en uno de los yacimientos estudiados, las diferencias reconocidas entre las pastas de un mismo yacimiento parecen obedecer a la distinta manipulación de las arcillas de una misma materia prima. Las fases minerales detectadas y las observaciones microscópicas han servido para estimar las condiciones de cocción de dichas pastas.
\end{abstract}

Palabras clave: Arqueometría, cerámica celtibérica, alfares, materia prima

Archaeometric study of five Celtiberian pottery production centres from Central Iberian's Chain.

The aim of this work is the archaeometric characterization of pottery production related with five local Celtiberian production centres from the Central Iberian's Chain. In these potter's workshops dated from the third to the second centuries BC, have been made wheel's pottery grouped in three main types of vessels: storage/transport, service and table. The main goal of this research is to characterize different ceramic pastes from a mineralogical, textural and chemical point of view, with the purpose to form reference groups from each production centre and to establish the technology of manufacture. The samples have been analysed using optical microscopy (OM), X-ray diffraction (XRD), textural analysis by means of an image digitalization system and chemical analyses by inductively coupled plasma-atomic emission spectrometry (ICP-AES). The results derived have allowed the recognition of eight different ceramic fabrics. All production centres used a mud clay raw material of illite-muscovite composition with very fine natural crushed inclusions of variable lithology. With the exception of one centre, the differences showed between pastes from the same atelier may be due to different manipulation of the same raw material. The minerals phases detected and microscopic observations have permitted to estimate fire conditions for the analyzed pastes.

Keywords: Archaeometry, Celtiberian pottery, production centres, raw material.

\section{INTRODUCCIÓN Y OBJETIVOS}

La existencia de alfares o centros de producción cerámica especializados, de época prerromana en la Península Ibérica, es un hecho bien conocido por la mayoría de los investigadores. No obstante, el número de alfares excavados en la Península Ibérica es reducido y en la gran mayoría de los casos de manera parcial, ya que existe un gran problema de conservación de las estructuras de estos yacimientos (1). En los últimos años estamos asistiendo a un crecimiento de los estudios sobre la alfarería prerromana en el área ibérica (2) y celtibérica (3-5). Las prospecciones arqueológicas desarrolladas en el Sistema Ibérico Central han permitido localizar 12 alfares, en su mayor parte inéditos, que están siendo estudiados de forma sistemática y global. La importancia del análisis de los materiales de estos yacimientos radica en la procedencia de los mismos ya que, por primera vez, se van a establecer las características físicoquímicas de las cerámicas celtibéricas, desde los propios centros productores y no desde los asentamientos receptores de estos productos $(6,7)$.

En el presente trabajo se ha realizado el estudio arqueométrico de la producción cerámica, en un total de 5 de los 12 alfares celtibéricos ubicados en el Sistema Ibérico Central. Los yacimientos incluidos en el estudio son: Barranco 
de la Cañada (Torralba de los Frailes, Zaragoza), Mojón de Ibdes II (Monterde-Llumes, Zaragoza), La Rodriga (Fuentelsaz, Guadalajara), Modojos II (Codes, Guadalajara) y Hortezuelas III (Ablanque, Guadalajara). Los dos primeros se localizan en la cuenca del río Piedra, mientras que los otros tres, pertenecientes a la provincia de Guadalajara, se ubican en las Parameras de Molina de Aragón. Ambos sectores se sitúan entre las Ramas Castellana y Aragonesa del Sistema Ibérico, donde afloran litologías de edad mesozoica (principalmente cretácicas), terciaria y cuaternaria capaces de suministrar materia prima para la fabricación cerámica (Figura 1).

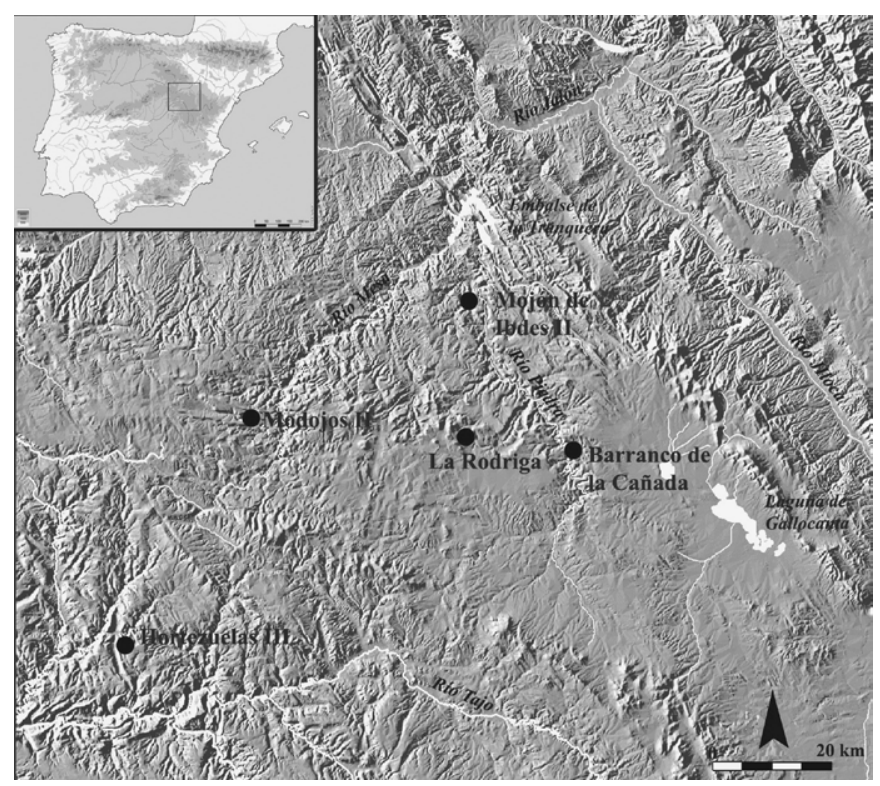

Fig. 1- Situación geográfica de los yacimientos estudiados.

Los materiales analizados proceden de los trabajos de prospección microespacial realizados recientemente en cada uno de estos yacimientos con la finalidad de identificar las características de cada complejo alfarero, la distribución espacial de las diferentes áreas funcionales (testar, hornos, almacén, etc), establecer la producción cerámica del mismo y la distribución de sus cerámicas (1). En estos talleres se fabricaban cerámicas finas a torno, cuya pasta presenta gran semejanza desde el punto de vista visual (color, cocción, tacto, inclusiones, etc). Las vasijas producidas en estos alfares son similares, estando presentes prácticamente todas las formas representativas del ajuar celtibérico que han sido estudiadas por grupos funcionales clasificados en vajilla de almacenaje/ transporte, vajilla de servicio y vajilla de mesa (8). Aunque se observa un claro predominio de tinajas sobre el resto de recipientes, también se documentan vasijas globulares, tinajas tipo ilduratin, soportes, jarras/enocoes, vasos caliciformes, vasos crateriformes, botellas, cuencos, copas, e incluso bolas de cerámica, fusayolas y pondus (Figura 2). La decoración empleada es la pintura aplicada directamente sobre la superficie de las vasijas o sobre el engobe, utilizando colores marrón, rojo y negro. A partir de los materiales de cada alfar se estima una cronología de funcionamiento de estos centros similar, centrada en los siglos III-II a. C., con probable inicio a finales del IV a. C. para el caso de Hortezuelas III y Modojos II y perduración hasta el I a. C. en La Rodriga (9), Mojón de Ibdes II y Barranco de la Cañada.

Este estudio pretende caracterizar las diferentes pastas cerámicas desde un punto de vista mineralógico, textural y químico, con el propósito de crear grupos de referencia de cada alfar y establecer los procesos tecnológicos empleados en su manufactura. Esta aportación se enmarca en un proyecto futuro más ambicioso que intentará, por una parte, comparar entre sí los grupos de referencia de cada alfar del Sistema Ibérico Central y, por otra, relacionarlos con los de los asentamientos de la región y establecer así la procedencia y distribución de cada producción alfarera.

\section{METODOLOGÍA EXPERIMENTAL}

\subsection{Selección de muestras}

TABLA I. CARACTERÍSTICAS DE LAS MUESTRAS SELECCIONADAS PARA LOS ANÁLISIS.

\begin{tabular}{|c|c|c|c|c|c|c|c|c|c|c|c|c|c|}
\hline \multirow{3}{*}{$\begin{array}{l}\text { Localización } \\
\text { Yacimiento }\end{array}$} & \multirow{3}{*}{ Muestra } & \multirow{3}{*}{$\begin{array}{l}\text { represent. } \\
\text { pasta }(\%)\end{array}$} & \multirow{3}{*}{ Tipología } & \multicolumn{10}{|c|}{ Color } \\
\hline & & & & \multicolumn{3}{|c|}{ Ext. } & \multicolumn{3}{|c|}{ Int. } & \multicolumn{4}{|c|}{ Corte } \\
\hline & & & & $\mathrm{L}^{*}$ & $a^{*}$ & $\mathbf{b}^{*}$ & $\mathbf{L}^{*}$ & $a^{*}$ & $\mathbf{b}^{*}$ & $\mathrm{~L}^{*}$ & $a^{*}$ & $\mathbf{b}^{*}$ & Munsell \\
\hline \multirow{3}{*}{$\begin{array}{l}\text { Torralba Frailes } \\
\text { Barranco Cañada }\end{array}$} & TFCa1 & $35 \%$ & Asa & 55.7 & 16.9 & 26.3 & 55.2 & 17.8 & 27.7 & 57.2 & 16.4 & 24.0 & 4,7 YR \\
\hline & TFCa2 & $61 \%$ & Vasija Globular & 66.4 & 12.1 & 28.1 & 67.5 & 13.0 & 30.5 & 69.0 & 7.5 & 21.1 & 9,1 YR \\
\hline & TFCa 3 & $4 \%$ & $\begin{array}{c}\text { Vaso } \\
\text { Caliciforme }\end{array}$ & 66.2 & 13.5 & 28.3 & 73.5 & 9.9 & 24.6 & 75.2 & 5.0 & 17.4 & 9,7 YR \\
\hline \multirow{3}{*}{$\begin{array}{c}\text { Monterde } \\
\text { Mojón de Ibdes II }\end{array}$} & Mo1 & $10 \%$ & Tinaja & 68.1 & 10.4 & 15.9 & 67.0 & 10.4 & 13.6 & 69.3 & 7.3 & 11.9 & 5,1 YR \\
\hline & Mo2 & $60 \%$ & Tinaja & 58.3 & 17.2 & 24.7 & 61.9 & 13.9 & 25.0 & 58.9 & 14.6 & 26.6 & $6,4 \mathrm{YR}$ \\
\hline & Mo3 & $30 \%$ & Ilduratin & 58.0 & 19.4 & 27.6 & 69.3 & 10.1 & 24.5 & 69.2 & 6.3 & 14.1 & $7,7 \mathrm{YR}$ \\
\hline \multirow{3}{*}{$\begin{array}{l}\text { Fuentelsaz } \\
\text { La Rodriga }\end{array}$} & FuRD1 & $48 \%$ & Vasija globular & 75.4 & 8.1 & 23.2 & 69.9 & 13.0 & 31.0 & 74.9 & 6.2 & 19.6 & 9,4 YR \\
\hline & FuRD2 & $26 \%$ & $\begin{array}{c}\text { Vaso } \\
\text { Caliciforme }\end{array}$ & 60.6 & 16.6 & 21.8 & 60.9 & 18.5 & 26.5 & 72.4 & 6.8 & 17.4 & $8,4 \mathrm{YR}$ \\
\hline & FuRD3 & $26 \%$ & Indeterminada & 54.3 & 23.0 & 29.1 & 62.6 & 11.3 & 26.4 & 69.6 & 7.8 & 17.0 & $7,7 \mathrm{YR}$ \\
\hline \multirow{3}{*}{$\begin{array}{c}\text { Codes } \\
\text { Modojos II }\end{array}$} & CoMD1 & $47 \%$ & Tinaja & 60.9 & 11.8 & 22.9 & 67.2 & 12.1 & 22.8 & 59.3 & 12.0 & 23.5 & $7,1 \mathrm{YR}$ \\
\hline & CoMD2 & $33 \%$ & $\begin{array}{c}\text { Vaso } \\
\text { Caliciforme }\end{array}$ & 57.3 & 11.3 & 18.8 & 62.5 & 14.1 & 26.4 & 54.8 & -0.9 & 4.2 & $0,1 \mathrm{GY}$ \\
\hline & CoMD3 & $20 \%$ & Tinaja & 56.5 & 16.5 & 23.4 & 63.7 & 16.8 & 24.4 & 56.8 & 14.0 & 20.8 & $4,8 \mathrm{YR}$ \\
\hline \multirow{3}{*}{$\begin{array}{c}\text { Ablanque } \\
\text { Hortezuelas III }\end{array}$} & $\mathrm{AH} 1$ & $20 \%$ & $\begin{array}{c}\text { Vaso } \\
\text { Caliciforme }\end{array}$ & 49.4 & 18.1 & 22.6 & 49.6 & 21.7 & 26.4 & 45.3 & 17.1 & 20.1 & $3,4 \mathrm{YR}$ \\
\hline & $\mathrm{AH} 2$ & $20 \%$ & Tinaja & 59.3 & 12.8 & 21.1 & 71.4 & 13.4 & 22.4 & 64.0 & 14.7 & 22.4 & 4,7 YR \\
\hline & $\mathrm{AH} 3$ & $60 \%$ & Tinaja & 67.7 & 5.5 & 19.3 & 54.7 & 7.7 & 19.9 & 70.0 & 8.9 & 16.3 & 6,4 YR \\
\hline
\end{tabular}


Las cerámicas han sido seleccionadas de forma aleatoria, a partir de los grupos de pastas establecidos previamente en cada alfar. Se han analizado tres muestras en cada uno de los 5 yacimientos. En la Tabla 1 se especifica el porcentaje de representación de cada pasta en su yacimiento. Las 15 muestras pertenecen a fragmentos de cerámicas elaboradas a torno encontrándose representados los distintos grupos funcionales referidos anteriormente (Figura 2).

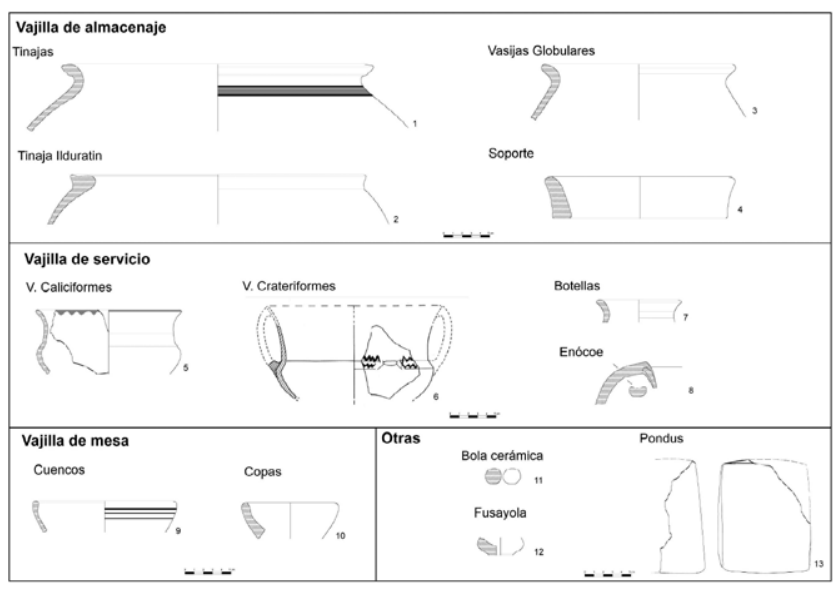

Fig. 2- Principales formas cerámicas documentadas en los alfares estudiados: Barranco de La Cañada $\left(n^{\circ} 4,5,7,9,10\right)$, Mojón de Ibdes II $\left(n^{\circ} 1,2\right)$, La Rodriga $\left(n^{\circ} 6(3), 8,12,13\right)$ y Modojos II $\left(n^{\circ} 11\right)$.

\subsection{Medida del color}

Se ha llevado a cabo un estudio detallado del color de cada muestra (parámetros cromáticos CIELAB76 L*, a*, b* y Munsell), incluyendo su superficie externa, interna y de la fractura una vez seccionada, con un espectrofotómetro Minolta CM-2600 d que opera con luz ultravioleta y condiciones de promedio de tres medidas simultaneas SCE (componente especular excluido) cada 0.5 segundos, observador a $10^{\circ}$, iluminante D65 y un área de medida de $3 \mathrm{~mm}$ (Tabla 1).

\subsection{Microscopía óptica de polarización}

El estudio petrográfico se ha realizado con un microscopio óptico de polarización, modelo Olympus AX70 con equipo de microfotografía. Las láminas delgadas se han elaborado con direcciones de corte perpendiculares a los bordes de los fragmentos utilizando, además, la tinción mixta con alizarina roja para la distinción de los carbonatos. El análisis petrográfico permite identificar los granos minerales y fragmentos de roca, que constituyen los desgrasantes del producto cerámico, así como observar las características ópticas de la matriz arcillosa, especialmente su birrefringencia, que denota su estado de cristalinidad o de vitrificación resultado del proceso de cocción (10). Es preciso advertir que en este estudio, el término "desgrasante" es utilizado en sentido amplio, como sinónimo de inclusión, sin especificar si fue añadido intencionadamente para modificar la plasticidad de las pastas o si ya formaba parte de forma natural de la materia prima original.

\section{4 Caracterización textural mediante tratamiento digital de imágenes}

El análisis textural se ha completado con el tratamiento digital de microfotografías representativas de las pastas, en condiciones de luz polarizada plana y cruzada. Estas imágenes han sido tratadas con el software informático de análisis Adimag 1.2., elaborado por el Servicio de Tratamiento Digital de Imagen de la Universidad de Zaragoza, que permite realizar la transformación de una primera imagen mediante la aplicación de una serie de parámetros (obtención de máscaras, segmentación, cribado, etc), hasta obtener la imagen final a partir de la cual se realizan los análisis morfométricos. Los valores obtenidos se recogen en una hoja de cálculo, para su posterior tratamiento y representación gráfica. Con el uso de esta técnica se pretende discriminar las pastas de cada centro de producción, por sus características texturales. Para ello se ha elegido como prototipo de cada alfar, la pasta más representativa por su abundancia. Cuando en un mismo centro se han observado texturas muy distintas, se ha realizado el tratamiento en varias muestras.

\section{5 Difracción de rayos $X$}

De forma complementaria se ha efectuado el análisis mineralógico mediante difracción de rayos $\mathrm{X}$ por el método de polvo convencional, determinándose tanto las fases de la muestra total (en polvo desorientado de muestra tamizada por debajo de $63 \mu \mathrm{m}$ ), como la mineralogía arcillosa (utilizando tres agregados orientados: sin tratamiento previo, con calentamiento a $550^{\circ} \mathrm{C}$ durante 2 horas y con impregnación de etilenglicol por contacto durante 12 horas). La preparación del agregado orientado incluye la extracción de la fracción arcilla $(<2 \mu \mathrm{m})$ mediante agitación mecánica por vía húmeda, decantación y el depósito de una parte de la suspensión resultante sobre una placa de vidrio.

Los registros difractométricos se han obtenido en un equipo Bruker D5005, trabajando a $40 \mathrm{Kv}, 30 \mathrm{~mA}$, utilizando radiación de $\mathrm{Cu} \mathrm{K} \alpha$ con monocromador primario, con ventanas fijas de $1^{\circ}, 1^{\circ}, 1^{\circ}, 0.15^{\circ}$ y $0.15^{\circ}$, en barridos continuos con paso angular de $0.04^{\circ}(2 \theta)$ y 4 segundos de tiempo de conteo. Los intervalos angulares registrados han sido de $4-64^{\circ}(2 \theta)$ para polvo de muestra total, $2-32^{\circ}(2 \theta)$ para agregado orientado normal, $2-22^{\circ}(2 \theta)$ para agregado calentado y $2-17^{\circ}(2 \theta)$ para agregado etilenglicolado. El difractómetro utilizado opera bajo el sistema Difracc-Plus, que incluye asimismo el software de tratamiento de datos Eva-Plus basado en el método de las intensidades de referencia $(11,12)$, con opciones de búsqueda en la base de datos ICDD. Para algunas comprobaciones en superficies planas del fragmento cerámico, se ha practicado análisis por microdifracción, utilizando un equipo Seifert 3003 TT (geometría Bragg-Brentano y configuración $\theta-\theta$ ), con tubo de $\mathrm{Cu}$, trabajando a $40 \mathrm{kV}$ y $40 \mathrm{~mA}$, con un dispositivo "single point", de modo que a la salida del haz se dispone un filtro de Ni y un colimador que focaliza la radiación X en un spot de entre 0.6-0.8 mm. La zona a analizar se posiciona adecuadamente mediante una tabla XYZ con motores de pasos para cada eje, y se emplea un detector posicional MBraun PSD-500 situado a $185 \mathrm{~mm}$ del centro del goniómetro. Los datos de difracción, tras adecuado cambio de formato, son tratados con el referido programa Eva-Plus.

\section{6 Análisis químico}

El análisis químico de las pastas se ha realizado mediante Espectrometría deemisión atómica con Plasma de acoplamiento inductivo (ICP-AES), con el instrumento Thermo Elemental Iris Intrepid Radial Spectrometer. Previamente, se tomó una pequeña parte del interior de la pieza cerámica para asegurar el 
análisis sólo de la pasta, especialmente en las piezas que lleven algún tratamiento o pigmento superficial. Esta operación se realizó mediante el eliminado de la capa superficial con una broca con cabeza de diamante y el corte con sierra de diamante de la pasta cerámica para la posterior trituración del fragmento en mortero de ágata. La disolución se llevó a cabo a partir de $50 \mathrm{mg}$ de cada muestra por ataque ácido en tubo abierto de Teflón. En el procedimiento seguido se añadieron inicialmente $3 \mathrm{~mL}$ de $\mathrm{HNO}_{3}(65 \% \mathrm{w} / \mathrm{v})$ y $2 \mathrm{~mL}$ de $\mathrm{HCl}(32 \% \mathrm{w} /$ v), calentando hasta sequedad. Posteriormente se añadieron 4 $\mathrm{mL}$ de HF (40\% w/v), llevándolos de nuevo hasta sequedad y repitiendo este paso tres veces, para finalmente colocar en el tubo $1 \mathrm{~mL}$ de $\mathrm{HNO}_{3}$ y $4 \mathrm{~mL}$ de $\mathrm{HClO}_{4}(60 \% \mathrm{w} / \mathrm{v})$ y calentar durante 1 hora, asegurando así la total disolución del residuo (13). Una vez que las muestras estuvieron disueltas, se llevaron a un volumen final de $50 \mathrm{~mL}$. En cada una de las disoluciones se determinaron los siguientes elementos: aluminio, calcio, magnesio, hierro, potasio, sodio, manganeso, titanio, bario y estroncio, siguiendo la correspondiente calibración mediante patrones analíticos..

\section{RESULTADOS}

\subsection{Caracterización petrográfica}

TABLA II. RESUMEN DE LOS RESULTADOS DEL ANÁLISIS PETROGRÁFICO DE LÁMINA DELGADA

\begin{tabular}{|c|c|c|c|c|c|c|c|c|c|c|c|c|c|c|c|}
\hline \multirow{2}{*}{$\begin{array}{c}\text { Yacimiento } \\
\text { Muestra }\end{array}$} & \multicolumn{3}{|c|}{ La Cañada } & \multicolumn{3}{|c|}{ Mojón de IbdesII } & \multicolumn{3}{|c|}{ La Rodriga } & \multicolumn{3}{|c|}{ Modojos II } & \multicolumn{3}{|c|}{ Hortezuelas III } \\
\hline & TFCa1 & TFCa2 & TFCa3 & Mo1 & Mo2 & Mo3 & FuRD1 & FuRD2 & FuRD3 & CoMD1 & CoMD2 & CoMD3 & AH1 & $\mathrm{AH} 2$ & AH3 \\
\hline Tipo pasta & 2 & 1 & $1--2$ & 2 & 1 & 2 & 1 & 1 & 1 & 1 & 2 & 1 & 1 & 1 & 1 \\
\hline Matriz (\%) & 88 & 73 & 76 & 87 & 75 & 90 & 86 & 83 & 84 & 85 & 75 & 85 & 90 & 87 & 88 \\
\hline Anisótropa & no & ligera & ligera & si & si & $\mathrm{Si}$ & si & si & si & si & $\begin{array}{c}\text { no/ } \\
\text { ligera }\end{array}$ & si & no & si & si \\
\hline Inclusiones (\%) & 12 & 27 & 24 & 13 & 25 & 10 & 14 & 17 & 16 & 15 & 25 & 15 & 10 & 13 & 12 \\
\hline$\square$ medio $(\mu \mathrm{m})$ & 100 & 100 & 100 & 60 & 100 & 50 & 50 & 75 & 75 & 75 & 75 & 75 & 75 & 75 & 75 \\
\hline$\square$ máx $(\mu \mathrm{m})$ & $<400$ & $<600$ & $<500$ & $<650$ & $<650$ & $<400$ & $<250$ & $<400$ & $<100$ & $<350$ & $<400$ & $<250$ & $<400$ & $<250$ & $<200$ \\
\hline \multicolumn{16}{|l|}{ Litología (\%) } \\
\hline Qtz & 4.5 & 11 & 9 & 7 & 7.5 & 6 & 7.5 & 9.5 & 9 & 6.5 & 10 & 9 & 4 & 8.5 & 8 \\
\hline $\mathrm{Kfs}$ & acc & 3.5 & 1 & acc & 2 & Acc & 0.5 & 0.5 & 0.5 & 2 & 3 & 0.5 & & 1 & 1 \\
\hline $\mathrm{Pl}$ & acc & 1.5 & acc & & acc & & acc & & & 1.5 & 1.5 & acc & & acc & acc \\
\hline FRCuarcítica & 1.5 & 2.5 & 2.5 & 0.5 & 1 & Acc & 1.5 & 1 & 1 & 1 & 2 & 1.5 & 2 & 0.5 & 0.5 \\
\hline FRArenítica & & acc & 1.5 & 1.5 & acc & 1 & & & & & & & & & \\
\hline $\begin{array}{l}\text { FRAren/ } \\
\text { Grauvaca }\end{array}$ & 2 & & & 0.5 & & & 1 & 1 & 1 & acc & & 1 & acc & & \\
\hline FRSilexítica+Fe & & & & & 2 & & & & & & & & acc & 0.5 & 0.5 \\
\hline FRCarbonatada & 4 & 1 & 4 & & 5 & Acc & 0.5 & 0.5 & acc & & 4 & & & & \\
\hline $\begin{array}{c}\text { Fases Fe }+ \\
\text { Opacos }\end{array}$ & acc & 3.5 & 5 & 3.5 & 5.5 & 3 & 1 & 4 & 4 & 3 & 4.5 & 3 & 3 & 2 & 1.5 \\
\hline Moscovita & acc & 4 & 1 & acc & 2 & Acc & 2 & 0.5 & 0.5 & 1 & Acc & acc & 1 & 0.5 & 0.5 \\
\hline Ocasionales & $\mathrm{Tu}$ & Cha & $\begin{array}{l}\text { Tu, } \\
\text { Cha }\end{array}$ & $\mathrm{Tu}, \mathrm{Zr}$ & Cha & & & & & $\mathrm{Tu}, \mathrm{Zr}$ & & Cha & & $\mathrm{Zr}$ & \\
\hline
\end{tabular}

$\mathrm{Qtz}=$ Cuarzo, $\mathrm{Kfs}=$ Feldespato potásico, $\mathrm{Pl}=$ Plagioclasa, $\mathrm{FR}=$ Fragmentos de roca, Fases $\mathrm{Fe}=$ Óxidos de hierro y fragmentos líticos ferruginosos. $\quad$ acc $=$

Accesorio, Tu = Turmalina, Cha = Chamota, $\mathrm{Zr}=$ Zircón.
En la Tabla 2 se resumen los datos de cada muestra analizada, con la cuantificación de sus componentes establecida por estimación visual bajo el microscopio óptico de polarización. Se expresan los porcentajes de matriz y de inclusiones respecto al total de la superficie analizada y se indican los tipos petrográficos establecidos en cada yacimiento. Se precisan los tamaños medios y máximos de las inclusiones, en cada muestra. Es preciso reseñar que el límite mínimo de tamaño observado ronda los $0.010 \mathrm{~mm}$, mientras que algunos autores incluyen como inclusiones los clastos con diámetro de grano $>0.015 \mathrm{~mm}(14,15)$.

En conjunto, el análisis de las láminas delgadas ha puesto de manifiesto que la totalidad de las cerámicas presenta inclusiones de litología variada con un tamaño medio de grano variable entre 50 y $100 \mu \mathrm{m}$, que corresponde respectivamente a las fracciones limo grueso $(0.0156-0.0625 \mathrm{~mm}) \mathrm{y}$ arena fina (0.0625-0.25mm). La cantidad de inclusiones es relativamente baja, variando entre un $10-27 \%$, con un rango de tamaño de grano máximo que oscila entre $100 \mu \mathrm{m}$ (arena fina) y $650 \mu \mathrm{m}$ (arena gruesa).

La naturaleza de las inclusiones es fundamentalmente silicatada, con predominio de cuarzo sobre feldespatos (ortosa y plagioclasas) y fragmentos líticos de rocas (cuarcíticas, areníticas y silexíticas). Presenta proporciones variables de fases que contienen hierro (en forma de óxidos de hierro 
y fragmentos líticos ferruginosos) y minerales opacos. Las micas tipo moscovita, aunque en distintas proporciones, están presentes en todas las pastas. Otros componentes con representación irregular son fragmentos de rocas carbonatadas. Con carácter ocasional se han identificado en muestras de algunos yacimientos turmalina, zircón y fragmentos reutilizados de cerámicas (chamotas).

En todas las pastas, el cuarzo monocristalino es el componente mayoritario de los desgrasantes. Las fases que contienen hierro y minerales opacos están presentes en todas las muestras con un tamaño de grano muy variable, desde la fracción limo a la de arena media $(0.25-0.5 \mathrm{~mm})$. Corresponden generalmente a fragmentos líticos ferruginosos que incorporan pequeños clastos de cuarzo. Geológicamente se atribuyen a paleosuelos donde es común esta asociación. Los feldespatos tanto potásico (tipo ortosa, y muy raramente microclina) como plagioclasas, se hallan en menor cantidad relativa que el cuarzo. Los fragmentos de rocas cuarcíticas y areníticas están presentes en todos los yacimientos. Los correspondientes a rocas detríticas tipo grauvaca, son característicos de La Cañada (Torralba) y minoritariamente de La Rodriga (Fuentelsaz). En cuanto a los fragmentos de rocas carbonatadas destacar que su contenido no es uniforme en las distintas pastas de un mismo yacimiento, no estando presentes en Hortezuelas III. Se distinguen dos tipos: fragmentos subredondeados de calcita de grano fino (mudstone) y fragmentos líticos carbonatados que incorporan cuarzos detríticos (grainstone). Estos últimos solo se han observado en la pasta mayoritaria del yacimiento de La Cañada. Según las condiciones de cocción experimentadas, las rocas carbonatadas aparecen parcialmente descompuestas a nodulizaciones de cal (16) que muestran una mayor porosidad creada por la disociación de los carbonatos. Estas nodulizaciones se recarbonataron con el paso del tiempo, observándose además la presencia de cristalización de calcita secundaria (17), de aporte externo, tapizando la porosidad en gran parte de las muestras estudiadas (Figura $3 \mathrm{~A})$. Por lo que se refiere a los fragmentos de rocas silexíticas presentan la peculiaridad de contener abundantes óxidos de hierro dispersos, habiéndose reconocido únicamente en los yacimientos de Mojón de Ibdes II y Hortezuelas III (Figura 3B).

Las morfologías de las inclusiones varían de angulosas a subangulosas para el cuarzo, feldespatos y fragmentos líticos silíceos y de subangulosas a subredondeadas para las fases de hierro-opacos y fragmentos carbonatados.

La matriz tiene una composición arcilloso-micácea con proporciones variables de óxidos de hierro y minerales opacos. Su comportamiento óptico es variable, pero preferentemente anisótropo frente a la luz polarizada lo que denotaría una temperatura y/o tiempo de cocción que no fueron lo suficientemente altos como para que se produjera la pérdida total de la estructura cristalina de los minerales de la arcilla. Los óxidos de hierro y opacos de mayor tamaño, tienen una distribución heterogénea en la matriz, mientras que los correspondientes a la fracción limo se encuentran homogéneamente dispersos en ésta. En particular, las pastas que han experimentado una cocción oxidante de mayor temperatura, muestran colores más rojizos, característica que se identifica en lámina delgada por la difusión del hierro en la matriz de estas pastas.

Bajo el microscopio, todas las pastas tienen una porosidad relativamente baja, no superando en ningún caso el $7 \%$ de la superficie analizada. La porosidad se observa en forma de vacuolas de desgasificación, ligeramente mayores que el tamaño medio de las inclusiones (limo grueso-arena fina), generalmente redondeadas y a veces elongadas. En algunas piezas cocidas a mayor temperatura se observa porosidad lineal, paralela a los bordes, generada presumiblemente por contracción en la cocción.

\subsection{Análisis textural}

La aplicación del tratamiento digital de imágenes es una herramienta muy útil para establecer diferencias entre distintas producciones cerámicas a través de la diferenciación de su análisis textural (18), fundamentalmente cuando dichas producciones presentan características composicionales similares. Asimismo, el análisis de la distribución de la granulometría de las inclusiones aporta información sustancial para la clasificación y el análisis de la tecnología utilizada en su producción (19).

Con este tratamiento se ha determinado la superficie ocupada por los desgrasantes midiendo todas las inclusiones que mostraban sus límites bien definidos. La proporción de matriz respecto a la de inclusiones se ha establecido por diferencia de la medida superficial ocupada por los desgrasantes. Los valores así obtenidos (Tabla 3) se ajustan, con bastante precisión, a los estimados por observación microscópica (Tabla 2). Para la realización del análisis granulométrico se han obtenido de cada tipo petrográfico dos máscaras complementarias, la correspondiente a los componentes opacos (en general fragmentos de rocas
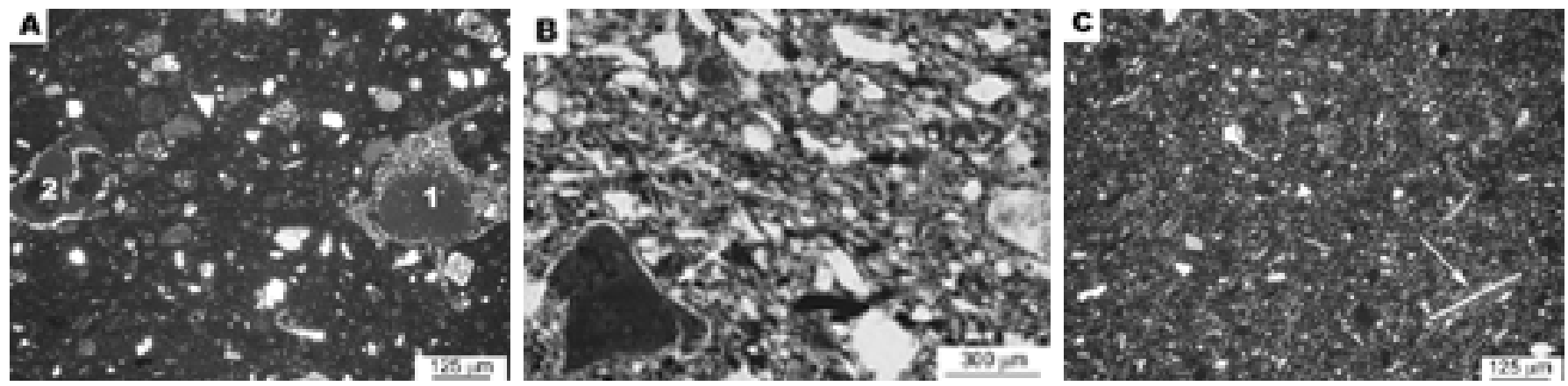

Fig. 3- Microfotografías representativas tomadas al microscopio petrográfico: A) Muestra TFCa1 (pasta 2); Nodulización de carbonato parcialmente descompuesta y recarbonatada (1) y porosidad tapizada por carbonato secundario (2). B) Muestra Mo2 (pasta 1); Aspecto característico en lámina delgada con inclusiones de fragmentos silexíticos como el indicado. C) Muestra FuRD1 (pasta 1); Se observa gran cantidad de inclusiones micáceas tipo moscovita con hábitos laminares.

Condiciones de luz polarizada plana (b) y luz polarizada cruzada (a y c). 
TABLA III. ESTIMACIÓN PORCENTUAL MEDIANTE TRATAMIENTO DIGITAL DE LAS DISTINTAS FRACCIONES GRANULOMÉTRICAS EN LOS GRUPOS PETROGRÁFICOS DESCRITOS.

\begin{tabular}{|c|c|c|c|c|c|c|c|}
\hline & & $\%$ limo fino & $\%$ limo grueso & $\%$ arena fina & $\%$ arena media & $\%$ total & $\%$ matriz \\
\hline \multirow{2}{*}{ TFCa1 } & Opacos & - & - & - & - & 0.00 & \multirow{2}{*}{88.96} \\
\hline & Resto Incl. & 0.80 & 7.41 & 2.84 & - & 11.04 & \\
\hline \multirow{2}{*}{ TFCa2 } & Opacos & 0.41 & 1.98 & 1.08 & - & 3.47 & \multirow{2}{*}{73.78} \\
\hline & Resto Incl. & 0.43 & 15.03 & 7.29 & 0.97 & 22.75 & \\
\hline \multirow{2}{*}{ Mo2 } & Opacos & 0.42 & 3.29 & 1.92 & - & 5.63 & \multirow{2}{*}{75.21} \\
\hline & Resto Incl. & 0.33 & 11.09 & 7.75 & - & 19.16 & \\
\hline \multirow{2}{*}{ Mo3 } & Opacos & 0.98 & 2.10 & 0.00 & - & 3.08 & \multirow{2}{*}{89.66} \\
\hline & Resto Incl. & 0.64 & 6.49 & 0.13 & - & 7.26 & \\
\hline \multirow{2}{*}{ FuRD2 } & Opacos & 0.67 & 2.78 & 0.25 & - & 3.70 & \multirow{2}{*}{82.86} \\
\hline & Resto Incl. & 0.73 & 11.24 & 1.47 & - & 13.44 & \\
\hline \multirow{2}{*}{ CoMD1 } & Opacos & 0.82 & 1.66 & 0.52 & - & 3.00 & \multirow{2}{*}{82.14} \\
\hline & Resto Incl. & 0.88 & 11.66 & 2.32 & - & 14.86 & \\
\hline \multirow{2}{*}{ CoMD2 } & Opacos & 0.51 & 3.13 & 0.87 & - & 4.50 & \multirow{2}{*}{74.98} \\
\hline & Resto Incl. & 0.72 & 16.28 & 3.52 & - & 20.52 & \\
\hline \multirow{2}{*}{$\mathrm{AH} 3$} & Opacos & 0.27 & 0.96 & 0.08 & - & 1.32 & \multirow{2}{*}{87.33} \\
\hline & Resto Incl. & 0.56 & 9.92 & 0.87 & - & 11.35 & \\
\hline
\end{tabular}

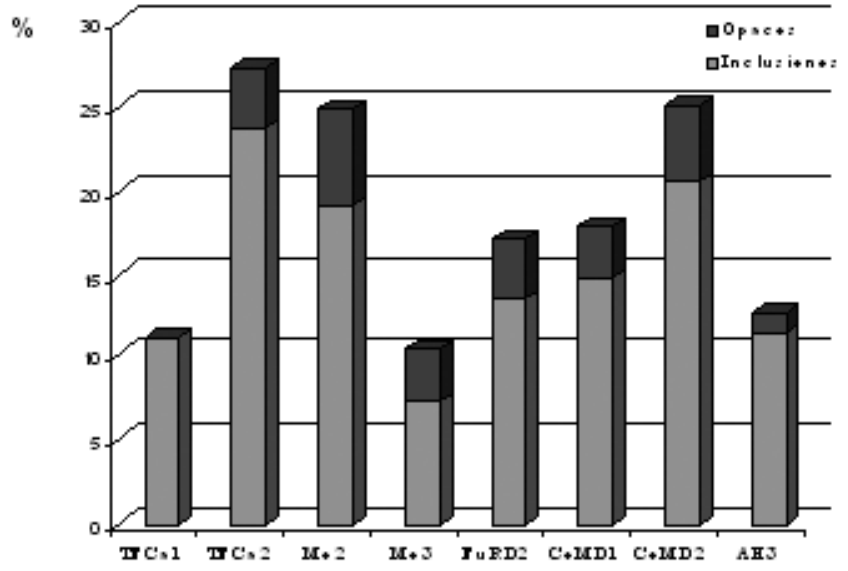

Fig. 4- Comparación entre la proporción de desgrasantes de fases que contienen hierro-opacos y resto de inclusiones en los distintos grupos cerámicos.

ferruginosas) y la del resto de inclusiones transparentes bajo lámina delgada. En la Figura 4 se representan conjuntamente los porcentajes de opacos y del resto de inclusiones de todos los centros productores.

En cuanto a la granulometría, se han establecido los siguientes rangos de tamaño de diámetro máximo para cada inclusión: arena gruesa $(>0.5 \mathrm{y}<2 \mathrm{~mm})$; arena media $(>0.25$ $-0.499 \mathrm{~mm})$; arena fina $(>0.0625-0.249 \mathrm{~mm})$; limo grueso $(>0.0156-0.0624 \mathrm{~mm})$ y limo fino $(<0.0156 \mathrm{~mm})$. En la Tabla 3 se recogen los porcentajes de las distintas fracciones de cada uno de los grupos petrográficos, de donde se sigue que no han sido detectadas inclusiones en la fracción arena gruesa. Las gráficas granulométricas se han realizado representando el conjunto de inclusiones separando las fracciones correspondientes a los distintos tamaños frente al porcentaje acumulativo (Figura 5).

\subsection{Estudio mineralógico mediante DRX}

En la Tabla 4 se recoge una estimación semicuantitativa

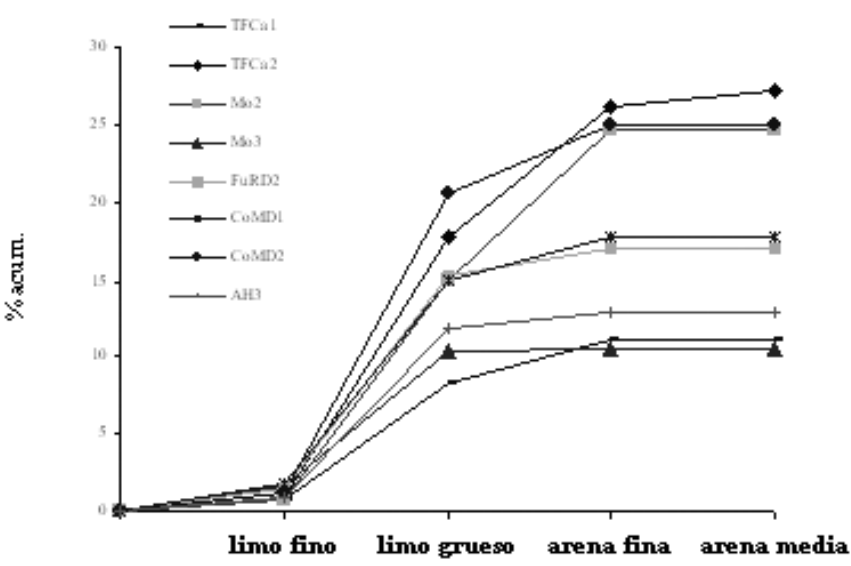

Fig. 5- Curvas granulométricas correspondientes a las distintas muestras cerámicas descritas. Se expresa en porcentaje acumulativo de las fracciones. Arena media $(>0.25-0.499 \mathrm{~mm})$; Arena fina $(>0.0625-0.249 \mathrm{~mm})$; Limo grueso $(>0.0156-0.0624 \mathrm{~mm})$ y Limo fino $(<0.0156 \mathrm{~mm})$.

de las fases cristalinas halladas mediante DRX. La asociación mineralógica detectada corrobora y amplía las observaciones realizadas bajo el microscopio óptico. Así, es preciso advertir que la mayor parte de la calcita detectada por DRX se refiere a la fase secundaria precipitada durante el enterramiento y que la original, observada bajo el microscopio en forma de grumos o nodulizaciones de reacción, ha sufrido también recarbonatación (17).

En cuanto a las fases de neoformación, producto del proceso de cocción, han sido identificados algunos minerales progrados tipo diópsido, gehlenita y wollastonita, cuya presencia es frecuente en cerámicas producidas a partir de arcillas ricas en calcio (20-24). Sin embargo, hay que señalar que el contenido de estos minerales en las cerámicas que nos ocupan es muy escaso y con un desarrollo muy incipiente. Incluso en algunas muestras, su existencia se ha expresado en forma de indicios, al detectarse en el estudio semicuantitativo. 
TABLA IV. RESULTADOS DE LOS ANÁLISIS DE DRX PARA MUESTRA TOTAL, AGREGADOS ORIENTADOS Y MICRODIFRACCIÓN DE MUESTRAS SELECCIONADAS.

\begin{tabular}{|c|c|c|c|c|c|c|c|c|c|c|}
\hline \multirow{2}{*}{ Muestra } & \multirow{2}{*}{ Qtz } & \multirow{2}{*}{$\begin{array}{l}\text { Fks } \\
\text { (Or) }\end{array}$} & \multirow{2}{*}{$\begin{array}{c}\mathrm{Pl} \\
\text { (An) }\end{array}$} & \multirow{2}{*}{ C } & \multirow{2}{*}{$\mathrm{Di}$} & \multirow{2}{*}{ W } & \multirow{2}{*}{$\mathrm{Ge}$} & \multirow{2}{*}{$\mathbf{H}$} & \multicolumn{2}{|c|}{ Fil. } \\
\hline & & & & & & & & & Ms & ill \\
\hline TFCa1 & +++ & + & ++ & ++ & ++ & - & + & ++ & + & - \\
\hline TFCa2 & +++ & +++ & +++ & + & + & I & - & + & + & + \\
\hline TFCa3 & ++++ & +++ & ++ & + & - & - & - & - & + & + \\
\hline Mo1 & ++++ & +++ & ++ & - & + & - & - & - & + & + \\
\hline Mo2 & +++ & ++ & +++ & + & + & I & + & ++ & + & + \\
\hline Mo3 & ++++ & +++ & + & - & + & I & - & - & + & + \\
\hline FuRD1 & ++++ & +++ & +++ & - & I & - & - & - & + & + \\
\hline FuRD2 & ++++ & ++ & - & + & + & I & - & - & + & + \\
\hline FuRD3 & ++++ & ++ & ++ & - & + & I & - & ++ & + & + \\
\hline CoMD1 & ++++ & +++ & + & - & + & I & - & ++ & + & + \\
\hline CoMD2 & ++++ & +++ & + & - & I & I & - & ++ & + & - \\
\hline CoMD3 & ++++ & +++ & ++ & - & + & + & - & + & + & + \\
\hline AH1 & ++ & ++ & + & + & + & I & - & ++++ & + & - \\
\hline $\mathrm{AH} 2$ & ++++ & +++ & + & - & + & + & - & +++ & + & + \\
\hline AH3 & ++++ & + & + & + & + & - & - & ++ & + & + \\
\hline
\end{tabular}

Estimaciones relativas a Qtz $=$ Cuarzo, Fks $=$ Feldespato potásico (principalmente ortosa), $\mathrm{Pl}=$ Plagioclasa (principalmente anortita), $\mathrm{C}=$ Calcita, $\mathrm{Di}=$ Diópsido, $\mathrm{W}$ $=$ Wollastonita, $\mathrm{Ge}=$ Gehlenita, $\mathrm{H}=$ Hematites, Fil $=$ Filosilicatos deshidroxilados (Ms $=$ moscovita, ill= illita)

Proporciones relativas: ++++: muy abundante; +++: abundante; ++: medio;

+: escaso; I: indicios; -: ausente

Únicamente el diópsido (Di) es la fase de alta temperatura que aparece en mayor o menor medida en todos los yacimientos estudiados.

De la información combinada entre las observaciones petrográficas y las fases cristalinas detectadas por DRX pueden concretarse aspectos sobre las condiciones de cocción de las pastas (21). La descomposición de los minerales de arcilla, y en particular la illita, comienza entre los 650 y $700^{\circ} \mathrm{C}$ (22). En torno a los $800^{\circ} \mathrm{C}$ y hasta los $950^{\mathrm{a}} \mathrm{C}$ va perdiendo progresivamente su cristalinidad, intervalo en el cual bajo el microscopio muestra un comportamiento óptico ligeramente anisótropo, con una débil pero perceptible manifestación de su birrefringencia. Sin embargo, cuando se ha alcanzado una temperatura de $950^{\circ} \mathrm{C}$, el colapso de su estructura cristalina $(20,23)$, se manifiesta por el comportamiento óptico isótropo de la matriz cerámica (18). Los incipientes cristales de neoformación por reacción de transformación de la matriz, resultan imperceptibles al microscopio óptico, sin embargo son detectados mediante DRX.

La disociación de los carbonatos con el calor, es otro de los aspectos que ayudan a concretar las condiciones de cocción de las producciones cerámicas $(23,24)$. Teóricamente, la calcita se descompone por completo en torno a $\operatorname{los} 870^{\circ} \mathrm{C}$, formando cal $(\mathrm{CaO})$ y desprendiendo $\mathrm{CO}_{2^{\prime}}$ (23) aunque su disociación comienza a temperaturas inferiores variando en función del tipo de atmósfera oxidante o reductora, y del tiempo que permanece en cocción la pieza cerámica. A temperaturas inferiores a $\operatorname{los} 850^{\circ} \mathrm{C}$, la hidratación del $\mathrm{CaO}$ puede ocasionar problemas ya que el proceso involucra un fuerte cambio de volumen por expansión (25). A mayores temperaturas, reaccionará con la sílice y alúmina de los minerales de arcilla, para formar minerales progrados como diópsido $\left(\mathrm{CaMgSi}_{2} \mathrm{O}_{6}\right)$, gehlenita $\left(\mathrm{Ca}_{2} \mathrm{Al}_{2} \mathrm{Si}_{2} \mathrm{O}_{7}\right)$, wollastonita $\left(\mathrm{CaSiO}_{3}\right)$ e incluso anortita $\left(\mathrm{CaAl}_{2} \mathrm{Si}_{2} \mathrm{O}_{8}\right)(20-24)$.

La presencia de fases deshidroxiladas de filosilicatos y el desarrollo incipiente de minerales de neoformación junto

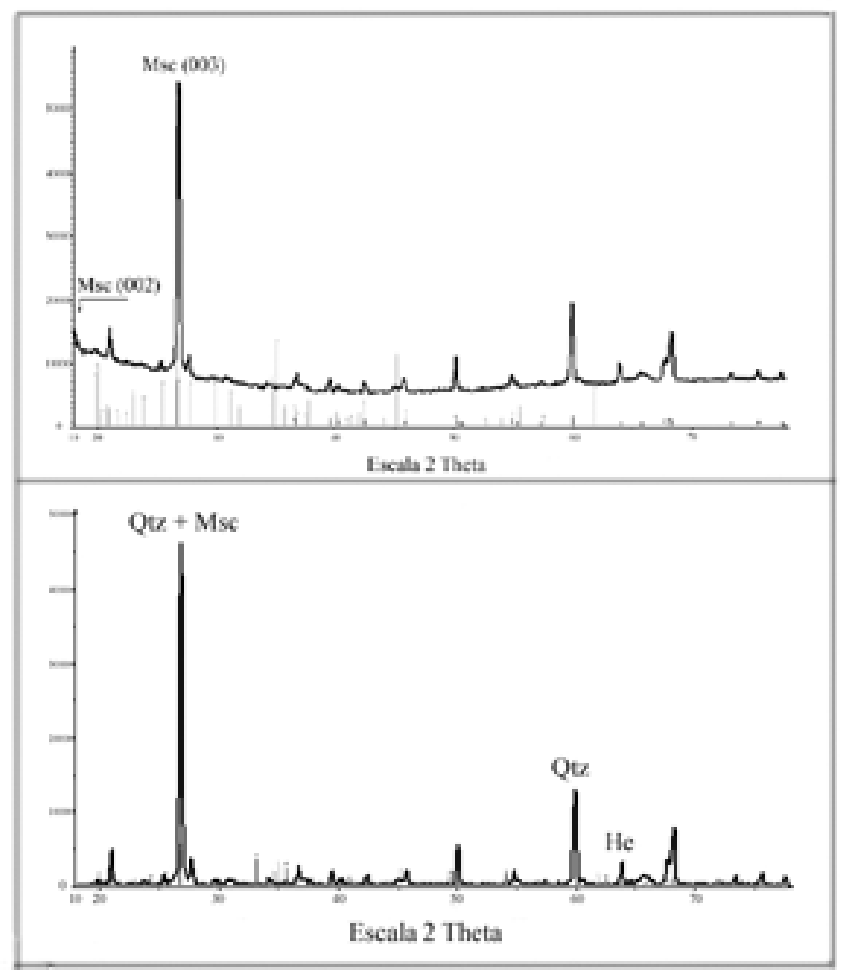

Fig. 6- Difractogramas de la muestra TFCa2 realizados mediante Microdifracción de rayos $\mathrm{X}$ en áreas seleccionadas.

$\mathrm{Qtz}=$ Cuarzo, $\mathrm{Msc}=$ Moscovita deshidroxilada, $\mathrm{He}=$ Hematites.

con la existencia de calcita parcialmente descompuesta en algunas muestras, traduce que las temperaturas máximas de cocción fueron relativamente bajas, como suele ser frecuente en materiales cerámicos procedentes de yacimientos arqueológicos. Así, la temperatura de cocción para la mayoría de las muestras cerámicas analizadas estaría comprendida entre los 850-900 ${ }^{\circ} \mathrm{C}$. Únicamente piezas minoritarias de algunos yacimientos podrían haber alcanzado una temperatura superior a este umbral o pudieron haber sido expuestas a un mayor tiempo de cocción. En particular, se trata de piezas en las que no se detecta illita (Tabla 4) y presentan, al microscopio óptico, un comportamiento isótropo de su matriz cerámica.

Los análisis de microdifracción corroboran la presencia de moscovita como fase micácea presente como desgrasante de todos los grupos estudiados (Tabla 4), (Figura 6). También se han analizado mediante esta técnica, los óxidos de hierro y fragmentos de rocas ferruginosas, poniéndose de manifiesto la existencia de hematites (Figura 6). Su presencia en proporciones variables puede inferirse de la propia observación del tono anaranjado o rojizo de las cerámicas, pero también en las pastas de tonos claros es relativamente abundante formando parte de la matriz y de los desgrasantes, como se ha puesto de manifiesto en el estudio petrográfico. 
TABLA V. RESULTADOS DE LOS ANÁLISIS QUÍMICOS MEDIANTE ICP-AES.

\begin{tabular}{|c|c|c|c|c|c|c|c|c|c|c|}
\hline & $\begin{array}{c}\mathbf{N a}_{2} \mathbf{O} \\
(\%)\end{array}$ & $\begin{array}{c}\mathbf{M g O} \\
(\%)\end{array}$ & $\begin{array}{c}\mathrm{Al}_{2} \mathbf{O}_{3} \\
(\%)\end{array}$ & $\begin{array}{c}\mathbf{K}_{2} \mathbf{O} \\
(\%)\end{array}$ & $\begin{array}{c}\mathrm{CaO} \\
(\%)\end{array}$ & $\begin{array}{c}\mathrm{TiO}_{2} \\
(\%)\end{array}$ & $\begin{array}{c}\mathbf{F e}_{2} \mathbf{O}_{3} \\
(\%)\end{array}$ & $\begin{array}{c}\mathbf{M n} \\
(\mathbf{p p m})\end{array}$ & $\begin{array}{c}\mathbf{B a} \\
(\mathbf{p p m})\end{array}$ & $\begin{array}{c}\mathbf{S r}_{\mathbf{r}} \\
(\mathbf{p p m})\end{array}$ \\
\hline TFCa1 & 0.19 & 7.07 & 15.90 & 3.94 & 6.76 & 0.71 & 6.54 & 504 & 370 & 997 \\
\hline TFCa2 & 0.15 & 0.67 & 8.49 & 3.19 & 0.77 & 0.40 & 1.4 & 80 & 382 & 107 \\
\hline TFCa3 & 0.12 & 0.75 & 11.76 & 1.21 & 2.50 & 0.81 & 2.3 & 80 & 272 & 194 \\
\hline Mo1 & 0.10 & 0.32 & 10.48 & 0.65 & 1.13 & 0.50 & 1.9 & 30 & 249 & 47 \\
\hline Mo2 & 0.15 & 0.70 & 13.16 & 2.59 & 3.01 & 0.64 & 4.01 & 100 & 380 & 70 \\
\hline Mo3 & 0.10 & 0.44 & 8.33 & 0.73 & 0.76 & 0.66 & 1.57 & 34 & 176 & 48 \\
\hline FuRD1 & 0.13 & 0.54 & 9.35 & 1.84 & 0.64 & 0.41 & 1.4 & 43 & 336 & 57 \\
\hline FuRD2 & 0.12 & 0.69 & 15.36 & 2.07 & 0.53 & 0.79 & 3.28 & 29 & 271 & 63 \\
\hline FuRD3 & 0.12 & 0.48 & 15.79 & 2.03 & 0.63 & 0.79 & 3.4 & 29 & 252 & 52 \\
\hline CoMD1 & 0.12 & 0.72 & 18.49 & 3.13 & 0.75 & 0.71 & 4.04 & 97 & 451 & 154 \\
\hline CoMD2 & 0.14 & 0.68 & 14.87 & 2.99 & 0.79 & 0.67 & 3.3 & 53 & 390 & 144 \\
\hline CoMD3 & 0.08 & 0.51 & 12.72 & 2.48 & 0.92 & 0.57 & 3.14 & 122 & 427 & 66 \\
\hline AH1 & 0.20 & 2.44 & 15.24 & 4.43 & 0.67 & 0.53 & 5.64 & 146 & 567 & 325 \\
\hline AH2 & 0.12 & 0.64 & 12.98 & 2.07 & 0.25 & 0.71 & 2.5 & 36 & 343 & 116 \\
\hline AH3 & 0.13 & 0.69 & 13.90 & 2.28 & 0.41 & 0.75 & 2.57 & 36 & 376 & 154 \\
\hline
\end{tabular}

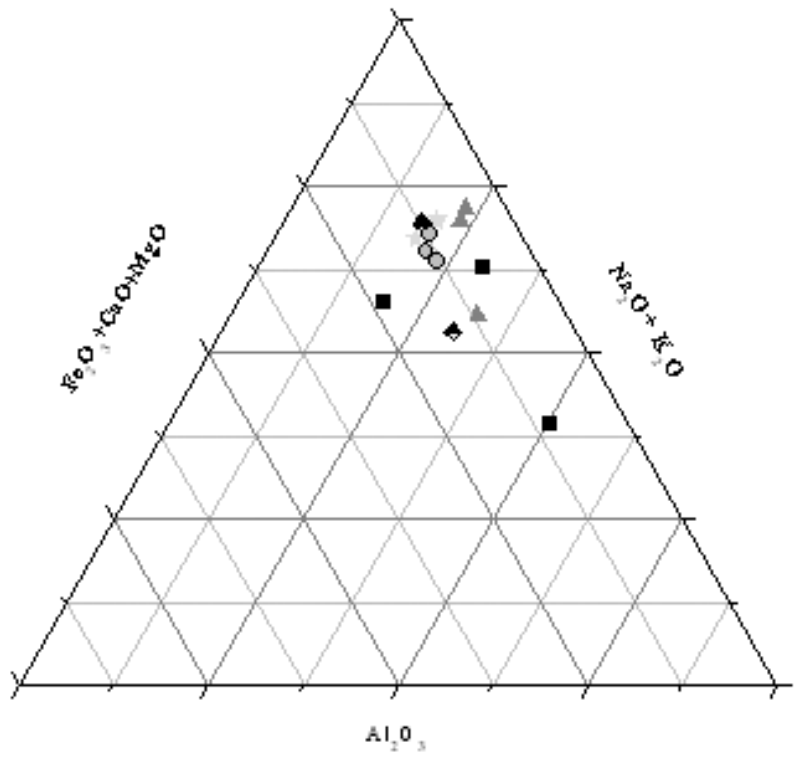

Fig. 7- Diagramas composicionales de a) $\mathrm{Al}_{2} \mathrm{O}_{3}-\left(\mathrm{Fe}_{2} \mathrm{O}_{3}+\mathrm{CaO}+\mathrm{MgO}\right)-\left(\mathrm{Na}_{2} \mathrm{O}+\mathrm{K}_{2} \mathrm{O}\right)$ y b) $(\mathrm{CaO}+\mathrm{MgO})-\mathrm{Fe}_{2} \mathrm{O}_{3}-\left(\mathrm{Na}_{2} \mathrm{O}+\mathrm{K}_{2} \mathrm{O}\right)$ a partir de los resultados de concentraciones en peso del análisis mediante ICP-AES.

\subsection{Análisis químico}

En la Tabla 5 y Figura 7 se recogen y representan los datos analíticos relativos a su composición química, donde puede apreciarse que, de acuerdo con las observaciones petrográficas, las variaciones composicionales de las pastas de cada yacimiento se traducen en una discreta dispersión de los valores de cada elemento químico analizado. Las mayores diferencias entre las muestras del mismo yacimiento se han obtenido en las muestras de Torralba (TFCa).
Se ha relacionado el contenido en $\mathrm{Fe}_{2} \mathrm{O}_{3}$ con los parámetros de color medidos en la sección cortada de las cerámicas, poniéndose de manifiesto una buena correlación entre dicho contenido químico y los valores positivos del parámetro cromático $\mathrm{a}^{*}$, que indican una coloración preferentemente rojiza $\left(+a^{*}\right)$ (Figura 8$)$. 


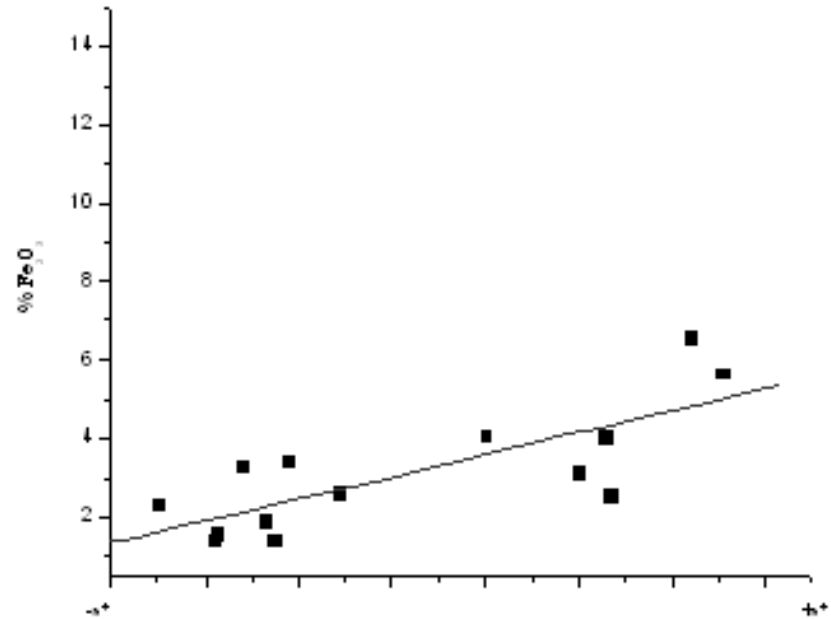

Fig. 8- Relación entre el contenido en $\mathrm{Fe}_{2} \mathrm{O}_{3}$ determinado mediante ICP-AES y el parámetro cromático a* en las muestras analizadas.

\section{DISCUSIÓN}

Los resultados obtenidos a partir de las distintas técnicas utilizadas han llevado a la distinción de 8 tipos de pastas cerámicas independientemente de su morfología o grupo funcional previamente establecido. En cada uno de los 5 yacimientos se ha determinado las características propias de cada tipo, dando preferencia a la pasta con mayor representación porcentual (tipo 1 de cada yacimiento). A continuación se discuten las principales características de cada centro de producción.

\subsection{Cerámicas del Barranco de la Cañada, Torralba de los Frailes (TFCa-)}

La producción cerámica de este alfar se caracteriza por presentar una matriz de composición arcilloso-micácea con contenido variable de fases de hierro y comportamiento óptico frente a la luz polarizada variable, desde ligeramente anisótropo a isótropo. Contiene un porcentaje irregular de inclusiones (12-27\%), con tamaños de grano medio en torno a $100 \mu \mathrm{m}$ (fracción arena fina), no superando el tamaño máximo de $600 \mu \mathrm{m}$ (Tabla 2). Del estudio conjunto de este yacimiento se desprende que deben separarse dos tipos de pasta bien distintos que, a su vez, denotarían la necesidad de buscar dos fuentes de suministro de materia prima distintas.

La pasta tipo 1, con una representación en el yacimiento del $61 \%$ (muestra TFCa2) presenta una cantidad alta de desgrasantes (en torno al 27\%, frente a un 73\% de matriz) con el contenido más bajo en $\mathrm{Al}_{2} \mathrm{O}_{3}(<9 \%)$, comparado con el resto de muestras analizadas. Destaca su abundancia en desgrasantes de feldespato potásico y moscovita, contribuyendo ambos al valor relativamente alto de $\mathrm{K}_{2} \mathrm{O}(>3 \%)$. Los fragmentos líticos carbonatados tanto mudstone como tipo grainstone, en concordancia con un contenido analítico muy bajo en $\mathrm{CaO}$ $(<0.8 \%)$. Los fragmentos líticos ferruginosos y minerales opacos predominan en la fracción limo grueso (Tabla 3). Respecto a la granulometría realizada con el programa Adimag 1.2. (Figura 5), esta pasta presenta una buena representación de todas las fracciones, con predominio de limo grueso y arena fina.

La pasta tipo 2, con 35\% de representatividad (muestra TFCa1) tiene unos valores relativamente altos de composición química en la mayor parte de sus componentes hecho que, unido a unas características petrográficas distintivas, hace que sea muy diferente al tipo 1 del mismo yacimiento y al resto de pastas estudiadas. Contiene un mayor porcentaje de matriz $(88 \%)$ que presenta un comportamiento isótropo frente a la luz polarizada. Es muy característico el alto contenido en fragmentos líticos carbonatados micríticos, semidescompuestos por el efecto térmico (Figura 3A), y cuya composición inicial pudo ser tanto calcítica como dolomítica, en concordancia con los valores en $\mathrm{CaO}(>6.6 \%)$ y $\mathrm{MgO}(>7 \%)$. Es destacable el valor de $\mathrm{Sr}$ (próximo a los 1000 ppm), en congruencia con el de $\mathrm{CaO}$. Otra peculiaridad es la presencia de fragmentos líticos areníticos tipo grauvaca, en tamaño arena fina. A diferencia de la pasta 1, no contiene fragmentos líticos ferruginosos como desgrasantes (Figura 4), pero presenta una matriz con una cantidad abundante de fases de hierro microcristalinas, detectadas mediante DRX y observadas bajo el microscopio óptico por la elevada pérdida de transparencia de la matriz. Químicamente, la abundancia de fases cristalinas de hierro se sigue igualmente por el alto valor de $\mathrm{Fe}_{2} \mathrm{O}_{3}(>6.5 \%)$. En cuanto a la granulometría obtenida mediante el tratamiento digital de imágenes, esta pasta presenta un bajo porcentaje en las fracciones de limo, como se pone de manifiesto al comparar su porcentaje acumulativo con el de otras pastas (Figura 5).

Por último destacar que la muestra TFCa3 (4\% de representatividad) participa de características intermedias entre las correspondientes a las dos pastas descritas.

\subsection{Cerámicas de Mojón de Ibdes II, Monterde (Mo-)}

La totalidad de las cerámicas de este yacimiento muestra un comportamiento birrefringente frente a la luz polarizada. Sus características granulométricas y composicionales separan dos pastas distintas.

La pasta tipo 1, tiene una representación en el yacimiento del $60 \%$ (muestra Mo2). Petrográficamente presenta un alto contenido en desgrasantes $(25 \%)$ con un tamaño medio en torno a $100 \mu \mathrm{m}$ y máximo $<650 \mu \mathrm{m}$. Además, la litología de las inclusiones remarca la diferencia con la pasta 2, por $\mathrm{su}$ alto contenido en fragmentos ferruginosos y minerales opacos y por la presencia de líticos carbonatados parcialmente descompuestos y de rocas silexíticas con óxidos de hierro dispersos (Figura 3B). Mediante la digitalización, el valor obtenido de opacos se distribuye mayoritariamente en las fracciones limo grueso y arena fina. Este contenido es acorde con la valoración de las fases cristalinas de hierro detectada mediante DRX, a la vez que corrobora el valor de $\mathrm{Fe}_{2} \mathrm{O}_{3}(>4 \%)$. Granulométricamente, mediante el tratamiento de imagen, esta pasta muestra los valores más altos en la fracción arena fina, con valores de $9.66 \%$ de un total de $24.79 \%$ de inclusiones (Tabla 3).

La pasta tipo 2 (muestras Mo1, Mo3), con una representación del $40 \%$, corresponde al tipo petrográfico definido por su menor tamaño de grano medio $(50 \mu \mathrm{m})$, aunque muy ocasionalmente presenta alguna inclusión cuyo diámetro máximo ronda las $650 \mu \mathrm{m}$ (Tabla 2). Esta pasta se caracteriza por su bajo contenido en inclusiones, en torno al $10 \%$, de composición fundamentalmente silicatada (cuarzo, feldespato potásico y escasos fragmentos de rocas cuarcíticas y areníticas), identificándose fragmentos de roca carbonatada con carácter muy accesorio. Respecto al contenido en fases que contienen hierro y opacos, es relativamente alto (en torno al $3 \%$ ) si se compara con la cantidad total de inclusiones, como 
queda reflejado en la Figura 4. Sin embargo, a diferencia de otras pastas, no se han medido opacos en la fracción arena (Tabla 3). Químicamente, presenta valores relativamente bajos en todos los elementos analizados (Tabla 5). En cuanto a su análisis granulométrico, se ha medido un tamaño de grano muy uniforme (exclusivamente limo) que facilita su reconocimiento en la Figura 5.

\subsection{Cerámicas de La Rodriga, Fuentelsaz (FuRD-)}

La producción cerámica estudiada en este yacimiento mantiene características bastante uniformes, que ha llevado a considerar un único tipo de pasta, representado por las tres muestras. Los fragmentos FuRD2 y FuRD3 son prácticamente idénticos, mientras que en la muestra FuRD1 se detectan muy ligeras variaciones. La matriz arcilloso-micácea de esta pasta mantiene el comportamiento anisótropo frente a la luz polarizada.

Las inclusiones presentan un tamaño de grano uniforme, mayoritariamente de arena fina (con un tamaño medio en torno a $75 \mu \mathrm{m}$ ) y cuya proporción varía entre el 14 y $17 \%$. El diámetro máximo no es uniforme de unas muestras a otras, pero no supera las $400 \mu \mathrm{m}$. Su composición es mayoritariamente de cuarzo, no superando el resto de componentes el $1 \%$, a excepción de los fragmentos líticos ferruginosos (Tabla 2). Los desgrasantes areníticos de composición grauvaca, corresponden a las inclusiones de mayor tamaño (fracción arena), no habiéndose detectado líticos silexíticos. Los fragmentos de roca carbonatada parcialmente descompuestos, son igualmente minoritarios, en coherencia con el bajo contenido en $\mathrm{CaO}(<0.7 \%)$. Las fases que contienen hierro y opacos tienen un tamaño de grano variable (fracciones limoarena fina) pudiendo aisladamente alcanzar las $350 \mu \mathrm{m}$. Es además característica la abundancia relativa de inclusiones de moscovita que pueden alcanzar $300 \mu \mathrm{m}$ de longitud (Figura $3 C)$.

Químicamente, las cerámicas estudiadas presentan valores muy uniformes (Figura 7), apartándose la muestra FuRD1 razonablemente en el valor de $\mathrm{Fe}_{2} \mathrm{O}_{3^{\prime}}$ de acuerdo con su bajo contenido en fases de hierro y opacos (Tabla 5). Mediante el tratamiento digital de imágenes la gráfica obtenida (Figura 5), equipara esta producción a la pasta 1 de Modojos II que se describe a continuación, separándose ambas del resto de producciones por su contenido total de inclusiones (en torno al 15\%), de las que es mayoritaria la fracción limo grueso, con una baja proporción de arena fina.

\subsection{Cerámicas de Modojos II, Codes (CoMD-)}

El conjunto de las muestras cerámicas estudiadas en este alfar se caracteriza por presentar una matriz de composición arcilloso-micácea con contenidos relativamente altos en fases minerales que contienen hierro, en congruencia con los valores obtenidos de $\mathrm{Fe}_{2} \mathrm{O}_{3}$ (3.14-4.04\%). Se han separado dos tipos de pastas atendiendo a la distinta proporción de desgrasantes, su granulometría y a la existencia, o no, de inclusiones de fragmentos de rocas carbonatadas. En común, las dos pastas presentan inclusiones con tamaño de grano medio en torno a $75 \mu \mathrm{m}$, además de carecer de fragmentos de rocas silexíticas (Tabla 2).

La pasta tipo 1, con una representación del $67 \%$ en el yacimiento (muestras CoMD1 y CoMD3) contiene un moderado porcentaje (15\%) de inclusiones, respecto a un $85 \%$ de matriz. Su comportamiento óptico es anisótropo, conteniendo abundantes fases de hierro difundidas homogéneamente en la matriz. Las inclusiones son de litología variada, con cuarzo y feldespatos además de fragmentos cuarcíticos, areníticos (incluidos de grauvaca) y de rocas ferruginosas y opacos. Es destacable que no presenta ni fragmentos de rocas carbonatadas ni silexíticas. Los contenidos químicos se mantienen uniformes en ambas muestras.

La pasta tipo 2, con una representatividad del 33\% (muestra CoMD2) presenta como característica distintiva, respecto a la pasta 1, un mayor porcentaje de inclusiones (25\%) frente a un $75 \%$ de matriz. Es señalable que su comportamiento óptico es mixto, con una zona central isótropa y otra marginal estrecha ligeramente birrefringente, característica que se manifiesta además visualmente con una doble coloración de la sección cerámica. Esta peculiaridad denota un cambio en las condiciones de cocción, mientras que la zona central presenta una coloración grisácea (posiblemente por su cocción reductora) por el contrario, en la zona marginal, el cambio a condiciones de menor temperatura y atmósfera oxidante permitió una mayor concentración de óxidos de hierro, mostrando una coloración más rojiza. Nótese que los parámetros de color expuestos en la Tabla 1, solo recogen las mediciones de la zona central grisácea, con valores negativos para el parámetro a*, debido a la imposibilidad de realizar la medición en la zona marginal de extensión milimétrica. Respecto a la litología de los desgrasantes, cabe señalar que no se han observado fragmentos de grauvaca y sin embargo contiene fragmentos de roca carbonatada semidescompuestos. Otro aspecto a reseñar es la alta proporción de fases que contienen hierro (fragmentos ferruginosos y opacos), siendo tras la pasta 1 de Monterde, la producción que mayor porcentaje presenta (Figura 4).

En cuanto a la granulometría, además de corroborar su alto contenido en inclusiones $(25.02 \%)$, es la pasta con mayor expresión porcentual de la fracción limo grueso (Figura 5), con valores de $3.13 \%$ de opacos y $16.28 \%$ del resto de inclusiones (Tabla 3).

\subsection{Cerámicas de Hortezuelas III, Ablanque (AH-)}

Las muestras $\mathrm{AH} 2$ y $\mathrm{AH} 3$, que suponen en conjunto un $80 \%$ de la producción del yacimiento, son muy homogéneas en todos los análisis efectuados, mientras que AH1 presenta ligeras variaciones composicionales así como una matriz que exhibe un comportamiento isótropo inducido por una mayor temperatura y / o tiempo de cocción. Por otra parte, la granulometría en las tres muestras es muy uniforme, por lo que se ha considerado un único tipo de pasta representativo de este taller.

Petrográficamente cabe destacar que las inclusiones presentan tamaño de grano uniforme, mayoritariamente de arena fina (con un tamaño medio próximo a $75 \mu \mathrm{m}$ ) y cuya proporción de inclusiones varía entre el 10 y 13\%. El diámetro máximo no supera las $400 \mu \mathrm{m}$ (Tabla 2). Como en el resto de producciones, la composición de las inclusiones es mayoritariamente de cuarzo, feldespatos y fragmentos de rocas cuarcíticas, a las que hay que añadir como característicos, los fragmentos de rocas silexíticas que contienen abundantes partículas de óxidos de hierro dispersos. Estos componentes silexíticos han sido descritos además en la pasta 1 de Monterde, pero a diferencia de ésta, en la de Ablanque no se han observado inclusiones de fragmentos de rocas carbonatadas, acorde con el bajo contenido en $\mathrm{CaO}(<0.67 \%)$. Tampoco se han distinguido fragmentos areníticos, aunque de forma accesoria 
se han identificado fragmentos de grauvacas (muestra AH1) que contribuyen a que esta muestra presente un mayor contenido en $\mathrm{MgO}$. Químicamente, salvo las diferencias ya mencionadas, las cerámicas estudiadas presentan valores muy uniformes, como se pone de manifiesto en la Figura 7.

Por otra parte, las gráficas obtenidas mediante el tratamiento digital de imágenes (Figuras 4 y5), completan su discriminación de la pasta 1 de Monterde (muestra Mo2), en la que también se han reconocido fragmentos silexíticos con óxidos de hierro (Tabla 2). Si analizamos la gráfica granulométrica de la Figura 5, la pasta de Ablanque (Hortezuelas III) podría equipararse a otras como las de Torralba (muestra TFCa1) y Monterde (Muestra Mo3), ya que las tres tienen en común el presentar un bajo porcentaje en inclusiones. Sin embargo, otros aspectos petrográficos ya mencionados en su caracterización, como la inexistencia de fragmentos silexíticos en estas dos últimas pastas, o el contenido en fragmentos carbonatados de la pasta de Torralba, completan la distinción entre ellas.

\section{CONCLUSIONES}

El análisis arqueométrico mediante la utilización de distintas técnicas analíticas ha resultado fructífero para la caracterización y discriminación de las pastas características de los cinco centros de producción de cerámica celtibérica de los siglos III-II a. C. Igualmente, ha proporcionado datos de gran interés para establecer los procesos tecnológicos empleados en su manufactura.

Las producciones cerámicas analizadas fueron elaboradas con arcillas illíticas ricas en moscovita y proporciones variables de carbonatos y minerales de hierro. Las distintas proporciones de fragmentos líticos ha permitido realizar diferenciaciones entre las producciones de los cinco yacimientos estudiados, si bien estas diferencias son muy sutiles y no deberían usarse como único criterio discriminante entre grupos de referencia. Sin embargo, la información combinada de las distintas técnicas utilizadas ha servido no sólo para caracterizar las ocho pastas diferenciadas, sino además para contrastarlas y discriminarlas entre sí.

Tanto la morfología con predominio de caras angulosas, como el tamaño homogéneo de las inclusiones, lleva a considerar que las pastas se elaboraron con depósitos arcillosos en los que previamente se había homogeneizado el tamaño de los desgrasantes por trituración, siendo por tanto estos desgrasantes inclusiones naturales fragmentadas mecánicamente junto con la materia prima arcillosa, proceso previo a la decantación de las arcillas. Dichas características revelan un modo de producción especializado mediante el uso de tecnologías homogéneas comunes a todos los centros productores estudiados. Salvo en el yacimiento de La Cañada (Torralba), las diferencias detectadas entre las pastas de un mismo yacimiento podrían obedecer a la distinta manipulación de los barros de una misma materia prima. Por otra parte, no parece existir relación entre el tipo de pasta utilizada y la morfología o función a la que estaban destinadas las piezas.

Las condiciones de cocción establecidas revelan una temperatura de cocción en un intervalo entre 850 y $900{ }^{\circ} \mathrm{C}$ para la mayor parte de las pastas analizadas, así como una atmósfera oxidante. La formación incipiente de minerales progrados indica que la temperatura de cocción superó los $800{ }^{\circ} \mathrm{C}$ aunque la detección de fases deshidroxiladas de filosilicatos tipo illita mediante DRX unida a las características birrefringentes de la matriz de las pastas, denotaría una temperatura de cocción que no superó los $900^{\circ} \mathrm{C}$. En algunos yacimientos se han reconocido pastas minoritarias que habrían superado este umbral de temperatura, o habrían estado expuestas a un mayor tiempo de cocción, casos como la pasta 2 de Barranco de la Cañada (Torralba de los Frailes), la pasta 2 de Modojos II (Codes) y excepcionalmente alguna pieza de la pasta de Hortezuelas III (Ablanque).

\section{AGRADECIMIENTOS}

Este trabajo se ha desarrollado gracias al Proyecto I+D: HUM 2005-03369/HIST financiado por el Ministerio de Educación y Ciencia y fondos FEDER y a la colaboración del grupo Hiberus de la Universidad de Zaragoza. Se agradecen los comentarios y sugerencias de los supervisores anónimos que han revisado el texto.

\section{BIBLIOGRAFÍA}

1. M. E Saiz Carrasco. “Propuesta de estudio a aplicar en los alfares del Sistema Ibérico Central”. Salduie 5, Universidad de Zaragoza, 113-130. (2005).

2. J. Coll Conesa. "Aspectos de tecnología de producción de la cerámica ibérica". Saguntum, Extra 3, 191-209, (2000).

3. Z. Escudero Navarro. "Consideraciones sobre la alfarería vaccea. La producción de cerámica a torno". Actas del IV Simposio sobre Celtíberos: Economía. Institución Fernando el Católico, Zaragoza, 241-257, (1999).

4. M. García-Heras. “Caracterización arqueométrica de la producción cerámica numantina”. BAR Internacional Series 692, Oxford, (1998).

5. M. García-Heras. "La tecnología cerámica". Celtíberos: Tras la estela de Numancia. Diputación Provincial de Soria, 359-366, (2005).

6. M. García-Heras. "Estudio arqueométrico de cerámica de Izana (Soria) y de otros yacimientos celtibéricos del Alto Duero". Bol. Soc. Esp. Ceram. V. 33 315-325 (1994).

7. M. García-Heras, J.A. Arenas, Ma.C. González, M. González Rodríguez. "La caracterización de materiales cerámicos del yacimiento celtibérico de "El Palomar" (Aragoncillo, Guadalajara): una producción especializada". Arqueometría y Arqueología. Universidad de Granada, 143-158, (1999)

8. M. A. Cano, R. López, M. E. Saiz. "La cerámica de técnica ibérica aparecida en las excavaciones de la ciudad de Segeda I. Área 3: Campaña 2001". Actas del XXVII Congreso Nacional de Arqueología, Bolskan, 19, t. II, pp. 211-220, (2002).

9. J. A. Arenas Esteban. "El alfar celtibérico de La Rodriga. Fuentelsaz, Guadalajara", Kalathos, 11-12, 205-232, (1991-1992).

10. P. Lapuente, M. P. Ramírez, P. Clark. “Caracterización de ladrillos de Monumentos Mudéjares en Calatayud, Zaragoza. Composición mineralógica y datación por termoluminiscencia", Bol. Soc. Esp. Min. 18, 41-54, (1995).

11. F. Barahona. "Arcillas de ladrillería de la provincia de Granada". Tesis doctoral, Universidad de Granada, 426 pp. (1980).

12. L. B. Davis, K. Smith. "Table of Experimental Reference Intensity Ratios". Powder Diffraction, 3, 201-206, (1989).

13. J. Pérez-Arantegui, M. I. Uruñuela, J. R. Castillo. “Roman Glazed Ceramics in the Western Mediterranean: Chemical characterization by Inductively Coupled Plasma Atomic Emission Spectrometry of ceramic bodies. J. Archaeol. Sci. 23, (6), 903-914, (1996)

14. M. Maggetti. "Phase analysis and its significance for technology and origin" in Archaeological ceramics (eds. J. S. Olin and A. D. Franklin), 121133. Smithsonian Institution Press, Washington, DC, (1982).

15. S. Pavía. "The determination of brick provenance and technology using analytical techniques from the physical sciences". Archaeometry 48, (2), 201-218, (2006).

16. S. Shoval, M. Gaft, P. Beck, Y. Kirsh. "Thermal behaviour of limestone and monocrystalline calcite tempers during firing and their use in ancient vessels". J. Thermal Anal. 40, 263-273, (1993).

17. S. Leguey, M. I. Carretero, B. Fabbri, E. Galán. “Caracterización mineralógica y química de los ladrillos de la Torre del Oro de Sevilla: una aproximación a la temperatura de cocción y orígen de las materias primas". Bol. Soc. Esp. Ceram. V. 40, 455-459, (2001)

18. P. Lapuente, J. Pérez-Arantegui. "Characterization and technology from studies of clay bodies of local islamic production in Zaragoza (Spain)". J. Europ. Ceram. Soc. 19, 1835-1846, (1999).

19. A. J. Polvorinos del Río, V. Flores, M. A. Tabales, M. J. Hernández. "Caracterización y tecnología de materiales cerámicos romanos de los ss. I a III d.C. procedentes del Hospital de las Cinco Llagas de Sevilla". Bol. Soc. Esp. Ceram. V. 42, 93-99, (2003).

20. T. Peters, R. Iberg. "Mineralogical changes during firing of calcium rich 
brick clays". Am. Cer. Soc. Bull. 57, 503-509, (1978).

21. M. M. Jordan, A. Boix, T. Sanfeliu, C. de la Fuente. "Firing transformation of Cretaceous clays used in the manufacturing of ceramic tiles". Appl. Clay Sci. 14, 225-234, (1999)

22. E. Galán, P. Aparicio. "Materias primas para la industria cerámica". Seminarios de la Sociedad Española de Mineralogía 2, 31-49, (2006).

23. G. Cultrone, C. Rodríguez-Navarro, E. Sebastián, O. Cazalla, M. J. de La Torre. "Carbonate and silicate phase reactions during ceramic firing". Eur. J. Mineral 13, 621-634, (2001)
24. M. P. Riccardi, B. Messiga, P. Duminico. "An approach to the dynamics of clay firing". Appl. Clay Sci. 15, 393-409, (1999).

25. E. Barahona, F. Huertas, A. Pozzuoli, J. Linares. "Firing properties of ceramic clays from Granada province, Spain. Miner. Petrogr. Acta, 29A, 577-590, (1985).

Recibido: 27.07.07

Aceptado: 27.11.07 


\section{Boletín de inscripción}

Empresa/Nombre:

Dirección:

Población: Provincia:

C.P.: C.I.F./N.I.F.:

Tel.: Fax.:

e-mail:

Persona de Contacto:

Productos que fabrica o transforma:

\section{Transferencia bancaria}

Señores les ruego que a partir de ahora y hasta nueva orden carguen a mi cuenta/libreta los recibos que tramite para su cobro la Sociedad Española de Cerámica y Vidrio. Marquen en el cuadro de cuotas el tipo de socio al que pertenecen

El abajo firmante manifiesta que conoce y acepta los términos contenidos en el Estatuto y Reglamento de la Sociedad Española de Cerámica y Vidrio y expresa su deseo explicito de pertenecer a ella en calidad de SOCIO.

Cta. $\mathrm{N}^{\circ}$.:

En caso de cta. situada fuera de España:

IBAN:

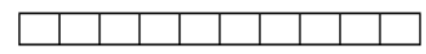

Código Swift.

\section{Sección de la Sociedad a la que desea pertenecer a efectos de voto:}

I. Arte y diseño.

II. Cerámica blanca, pavimentos y revestimientos cerámicos.

III. Ciencia básica.

IV Esmaltes y pigmentos cerámicos.

ㅁ. Materias primas.

VII. Refractarios.

V. Ladrillos y tejas.

ㅁ. VIII. Vidrios.

IX. Electrocerámica

ㅁ. X. Medio ambiente

\section{Cuadro de Cuotas}

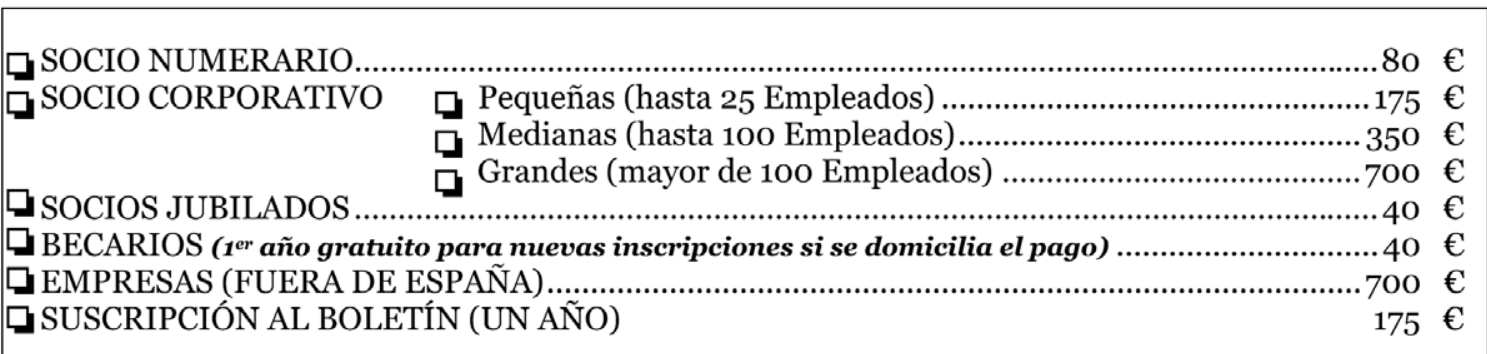

Sociedad Española de Cerámica y Vidrio. Instituto de Cerámica y Vidrio. Camino de Valdelatas s/n • 28049 Madrid

Tinos.: +34917355840 Y +34917355860 . Fax: +34917355843

web: www.secv.es - e-mail: secv@icv.csic.es

C.I.F.: G-28200327 